\title{
A Computer Program Development for a Garment's Pre-Cost Account Calculation in Apparel Industry
}

\author{
Emine Rümeysa Eren ${ }^{1}$, Oktay Pamuk ${ }^{2}$ \\ ${ }^{1}$ Marmara University, Vocational School of Technical Sciences, Clothing Production Technology Department, İstanbul, Turkey \\ ${ }^{2}$ Ege University, Faculty of Engineering, Textile Engineering Department, İzmir, Turkey
}

Corresponding Author: Emine Rümeysa Eren, rumeysa.eren@marmara.edu.tr

\begin{abstract}
The minimum difference between the pre-cost and actual cost in the apparel sector is very important for the enterprises to sustain their profitability. The fact that the estimated unit cost calculation requirement is very frequent and continuous in an environment where competition is increasing rapidly increases the workload of enterprises. In order to be able to take orders, companies must calculate the pre-cost estimation as close as possible to the actual cost. At this stage, companies encounter problems in fabric cost estimation which has the largest share especially in product cost. In this study, a computer program, which will be used in both weaving and knit top clothing group, has been formed in order to lighten the loads of apparel companies on the pre-unit cost calculation. The interface of the computer program is formed in C \# programming language using Visual Studio and DevExpress programs. The most important attribute of this program is that, it can calculate the product unit fabric quantity and marker efficiency by using only the product measurement table without the need of a model design department. In order to achieve this, equations were created in the area of calculation of product pattern areas. The program incorporates all cost components in a progressive calculation and consequently presents a product pre-cost report. The computer program was performed in two companies that work in the field of export of woven and knit top apparel in Izmir. The data obtained from the program were compared with the actual data from the companies.
\end{abstract}

\section{ARTICLE HISTORY}

Received: 04.12.2018

Accepted: 21.05.2019

\section{KEYWORDS}

Product cost in apparel, unit cost, preliminary cost, computerized cost calculation, cost of fabric, amount of unit fabric

\section{INTRODUCTION}

Quality, time and price are the most important components of apparel export. Continuously changing sector with competition has shown that time management is very important for companies [1-3]. The high quality products and services that the customers want, should be realized with the fast production, the planned term and the low price policy brought by the minimum cost. In a challenging competition environment, it is possible to increase and increase earnings with low cost $[4,5]$. Companies aiming to create a successful product at all stages from design to production, from marketing to sales, should be controlled, attentive and fast in terms of cost and price calculation [6, 7].
Apparel companies, which are manufacturing subcontracting to big brands, firstly calculate the cost of product and offer price to the brand. The customer can receive a price offer from more than one manufacturer at the same time. At this stage, the apparel company makes the unit pre-cost estimation of product. In the preliminary cost calculation process, the company which wants to get the confirmation of the order before the competitors, makes cost estimation by using cost data of previous products similar for the planned product [8].

The components of product cost should be determined for calculate the cost of a product and analyze its cost. These components can be classified into two groups: production cost covering direct materials, direct labor and general production costs; and period costs covering research and

To cite this article: Eren, E R., Pamuk, O. 2019. A computer program development for a garment's pre-cost account calculation in apparel industry. Tekstil ve Konfeksiyon, 29(2), 171-180. 
development, marketing, and general administrative expenses [9-13]. All types of fabrics used in the apparel companies are direct material cost. For this reason, the most important factor to be taken into account when calculating the preliminary cost is the determination of fabric costs [14-16].

The difficulties faced by the apparel companies during the cost estimation calculation are as follows.

- Pressure for quick return to customers

- Using estimated values based on past product information in pre-cost calculation

- Difficulty of accessing previous data and lack of database

- Difficulty in calculating fabric cost and taking the most time in cost calculation

- Difficulty in estimating the amount of product unit fabric

- There is not enough time for product pattern operation to determine actual unit fabric quantity

- To learn the amount of unit fabric amount to install extra work to the pattern design section, workflow disruption and overtime to cause

- Due to the time limitation, the determination of the amount of unit fabric depends on the estimation of the responsible person performing the pricing study and this situation also changes with the experience of the employee and the error rate increase.

- Lack of adequate inspection of other cost components due to the large amount of time spent on fabric cost

- Cost components are not significantly integrated in the computer environment [8, 17].

These reasons affect the difference between the pre-cost and the actual cost. The smaller the pre-cost is from the actual cost, the greater the profit of the company. It is within the acceptable limits that there is a $10-15 \%$ difference between the actual cost value generated for production and the pre-cost value given in the price offer [18].

In the apparel industry, computer aided studies to calculate the unit cost of the product has been studied. Başer and Bulgun prepared a package program to assist apparel companies in the design and order acceptance process. With the help of this program, enterprises can easily archive the parameters related to the production and design in their hands and they will be able to create the data of the new product quickly and consciously by utilizing the data of similar models which were produced in the case of a new product design and production [19]. Vuruşkan examined the production parameters in knitwear apparel companies by defining the unit costs and developed a software to calculate the unit costs of garments and make the cost estimates. The program is prepared as a web-based application in order that the supplier, the manufacturer and the customer can have the opportunity to communicate through the same platform [20]. Savaş developed a cost accounting model in order to find out the actual product costs by examining the production data and accounting data in a knitted apparel company. This system has been turned into a computer software. In this program, the production data is entered by the user and the product costs are calculated. In addition, the program allocates the most suitable products to the capacity of the company and enables the company to reach the maximum profit [18]. Dayanıklı developed a method for calculating fabric unit quantity by creating a computer software without any need for patterndrawing only using customer technical file and estimating marker productivity in denim pants and skirt product group [16]. Çelik and Değirmenci have designed a cost calculator which can make the unit cost of knitted and two-strand knitted fabrics, which are generally used to produce daily garments, in seconds. The interface of this software is written with Delphi 7 programming language with Windows compatible [21]. Özdemir, Utkun and Yeşil have prepared a program to calculate the unit cost of the products produced by small weaving companies. The interface of this program is built in ASP.NET programming language using Microsoft Visual Studio 2013 application development software [22].

Within the scope of this study, it is aimed to design a computer program which can enable to obtain unit pre-cost of the product quickly for to give speed and accuracy benefits to apparel companies at both weaving and knitted fabric type. The aim of this program is to create a way to calculate the cost of the fabric quickly and without the opportunity for the experience and subjective evaluations of all marketing purchasing employees. In addition, this program aims to minimize the need for an extra-desired pattern design study from the model design section to determine the estimated fabric amount. With the addition of other cost components together with the cost of the fabric, it is aimed to calculate and archive the product unit pre-cost in the closest way to reality. Thus, the workload will be reduced, the customer will be given a fast return and the pricing information can be given at the nearest values to the reality.

\section{MATERIAL AND METHOD}

In this study, a research has been conducted to quickly calculate the pre-cost based on different models of shirts and T-Shirts. Within this framework, the study has been conducted on a total of 22 models 12 of them being shirts and $10 \mathrm{~T}$-Shirts. The garments have been taken from two apparel export companies located in Izmir. While choosing the model, a variety of different styles including the product groups for different customers (men, women, kid) and model styles was chosen. Companies are used as the main size in the pattern design studies of the middle size of the size table in the product technical file. Table 1 and 2 show the technical proporties of models for the shirt and T-Shirt. 
Table 1. Technical proporties of shirt models

\begin{tabular}{cccccc}
\hline Model Code & $\begin{array}{c}\text { Product } \\
\text { Group }\end{array}$ & Size Number & Fabric Type & Model Description & Added Operation \\
\hline S1 & Man & L & Woven & Yoke, long sleeves, collar & - \\
S2 & Woman & S & Woven & Yoke, short sleeves, collar & - \\
S3 & Woman & 38 & Woven & Long sleeves, collarless & - \\
S4 & Woman & 38 & Woven & Sleeveless, collarless & - \\
S5 & Woman & S & Woven & Sleeveless, collarless & - \\
S6 & Woman & S & Woven & Yoke, long sleeves, collar & Garment wash \\
S7 & Baby boy & $9-12$ Month & Woven & Yoke, long sleeves, collar & Embroidery \\
S8 & Baby boy & $9-12$ Month & Woven & Yoke, long sleeves, collar & Embroidery \\
S9 & Boy kid & S & Woven & Yoke, long sleeves, collar & Embroidery, garment wash \\
S10 & Boy kid & S & Woven & Short sleeves, collarless & Embroidery, garment wash \\
S11 & Boy kid & L & Woven & Yoke, short sleeves, collar & Embroidery \\
S12 & Boy kid & S & Woven & Yoke, long sleeves, collar & \\
\hline
\end{tabular}

Table 2. Technical proporties of T-Shirt models

\begin{tabular}{cccccc}
\hline Model Code & $\begin{array}{c}\text { Product } \\
\text { Group }\end{array}$ & Size Number & Fabric Type & Model Description & Added Operation \\
\hline T1 & Man & L & Knitted & Yoke, long sleeves, collar & Garment wash \\
T2 & Woman & 46 & Knitted & Short sleeves, collarless & - \\
T3 & Woman & 46 & Knitted & Short sleeves, collarless & - \\
T4 & Woman & 46 & Knitted & $3 / 4$ sleeves, collar & Print \\
T5 & Woman & 48 & Knitted & Short sleeves, collarless & - \\
T6 & Woman & 46 & Knitted & Short sleeves, collarless & - \\
T7 & Woman & 48 & Knitted & Sleeveless, collarless & Print \\
T8 & Woman & 46 & Knitted & Short sleeves, collarless & Print \\
T9 & Woman & 46 & Knitted & Short sleeves, collarless & Embroidery, print \\
T10 & Woman & 46 & Knitted & Short sleeves, collarless & \\
\hline
\end{tabular}

In this study, the cost components of the products examined were analyzed. According to the results of the analysis, it is aimed to create a computer program with archival feature that will calculate the estimated unit fabric amount objectively and also integrate other cost components and generate unit cost estimate. The interface of this program has been prepared in $\mathrm{C}$ \# programming language using Visual Studio application development software and DevExpress additional program in report generation. The design of the application is created in a format that can be viewed in Windows environment.

In Figure 1, the program called Quick Forecasting Module (HTM), which has a opening screen, consists of three main sections: New Model, Settings and Search. The program can calculate the unit fabric requirement of a product, the cost of the unit fabric, the cost of the unit accessory, the unit labor cost and the unit overhead cost. Fabric, accessory and overhead archive section allows the company to create its own fabric and accessory information archive.

The New Model interface section is used for the first time to calculate the cost. This interface consists of 7 stages including general specifications, pattern information, measurement information, fabric information, accessory information, workmanship information and overhead. In this section, the information of the product is entered into the system by the user and the computer program calculates the estimated unit cost of the product. The Settings interface section is the section to enter data before starting the cost account. This interface consists of fabric storage, materialaccessory storage and overhead information sections. This information will be used both in the cost calculation phase and in the form of a special archive for the enterprise. The Search interface section is the search section for the cost account completed and saved models.

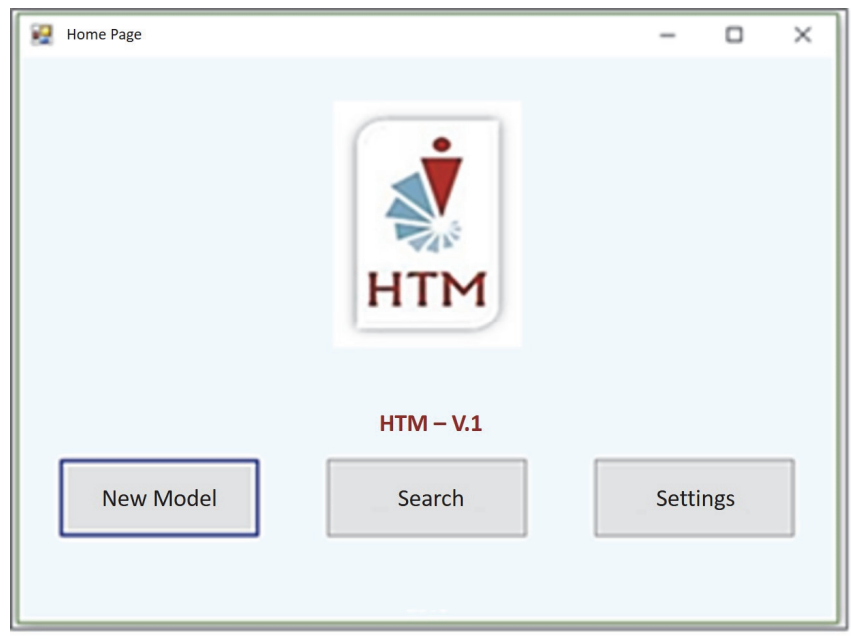

Figure 1. HTM programme's splash screen 
The designed work flow chart of the computer program for the estimated cost and price calculation of a new product is shown in Figure 2.

In the New Model section of the computer program, a method has been created to calculate the amount of fabric. The first step of the New Model section of the computer program is to enter the model information into the system.
At this stage, it is important to enter the product group into the system as woven/knitted and as a woman/man/kid/baby. The second step is to enter the pattern information into the system. At this stage, the pattern properties of the product are selected from the table and the number of pieces is entered. The pattern information page is shown in Figure 3.

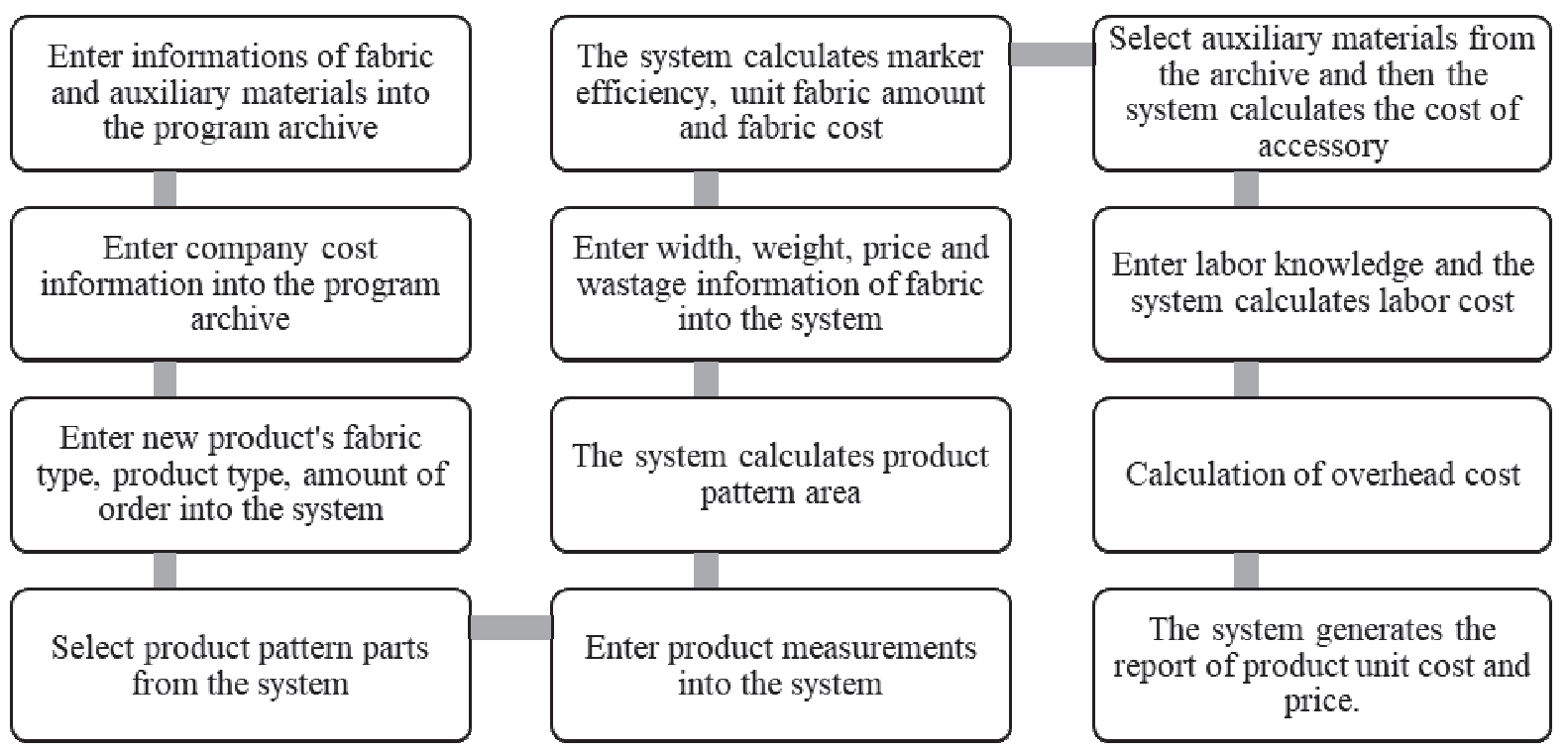

Figure 2. Work flow chart of HTM

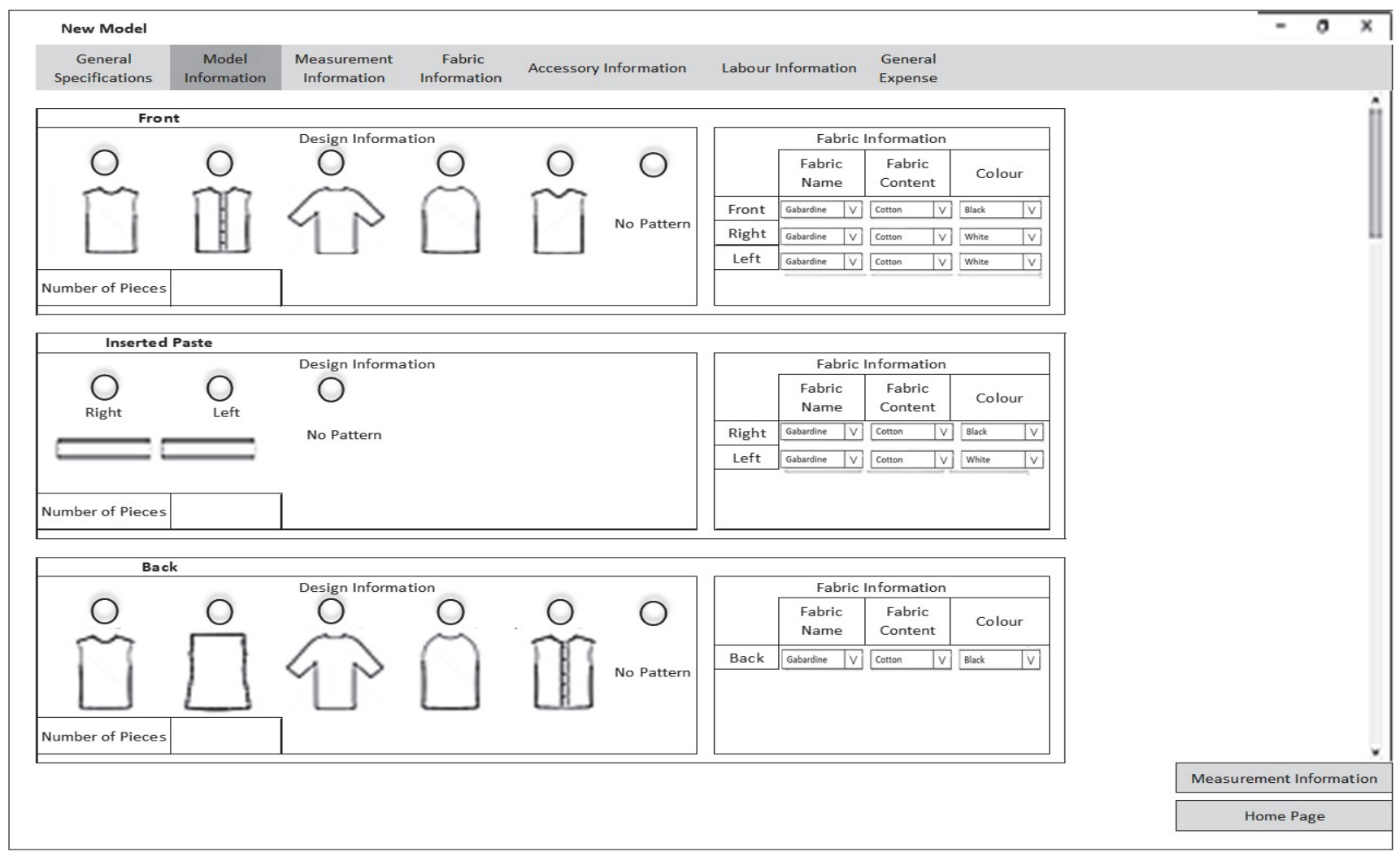

Figure 3. Pattern information interface page 
The third stage is to enter the measurement data into the system and then calculate the pattern area. The product technical file and the sample are sufficient for the computer program to calculate the areas of the pattern parts forming the product. Equations, that can calculate the area of each pattern part, are formed using the measurement information and sewing characteristics in the technical file. The areas of the pattern parts are formulated according to geometric shapes. Where the whole piece is not similar to the geometric shape, the parts are divided into segments and converted into smaller geometric shapes. Figure 4 and
Equation 1 show the method for front and back body pattern work (sa: seam amount). The areas of all parts of the selected models are calculated with the equations created. Special equations are designed for all options (front-back body, yoke, arm, cuff, collar, pocket etc.).

Figure 5 shows the measurement information page. After the measurement values and the suture shares are entered into the system, the system calculates the total area of the product with the formatted equations in the background (an example shown in Figure 4).
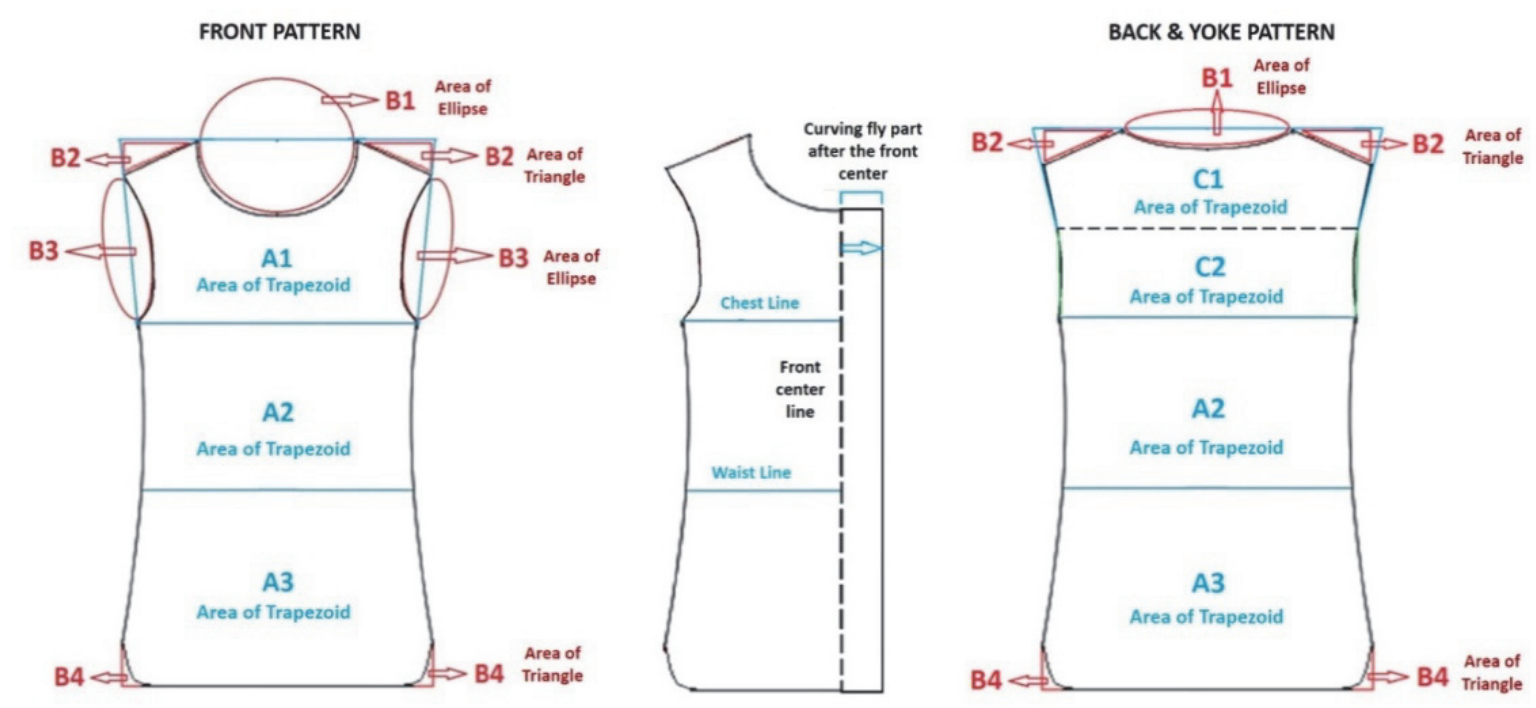

Figure 4. Example geometrical shapes of pattern part area calculation

Equation 1, 2, 3, 4 and 5 which are some of the designed equation examples (related to the front and back pattern) are shown below.

\section{Equation 1:}

$A 1=[(2 \times($ Straight shoulder width + sa $)+$ Neckline width + Chest width $+s a) \times($ Arm hole + Shoulder slope $)] \div 2$

Equation 2: $B 1=\frac{\{[\text { Neckline width } / 2)-s a] \times(\text { Neckline depth }-s a) \times \pi\}}{2}$

Equation 3: $B 2=\frac{\text { Shoulder slope } \times \text { Straight shoulder width }}{2}$

\section{Equation 4:}

$C 1=[($ Back shoulders width $+s a+$ Back width at half back armhole point $+s a) \times($ Yoke height $+s a)] \div 2$

\section{Equation 5:}

$C 2=\frac{(\text { Back shoulders width }+s a+\text { Chest width }+s a) \times \text { Chest position in the back }}{2}$ 


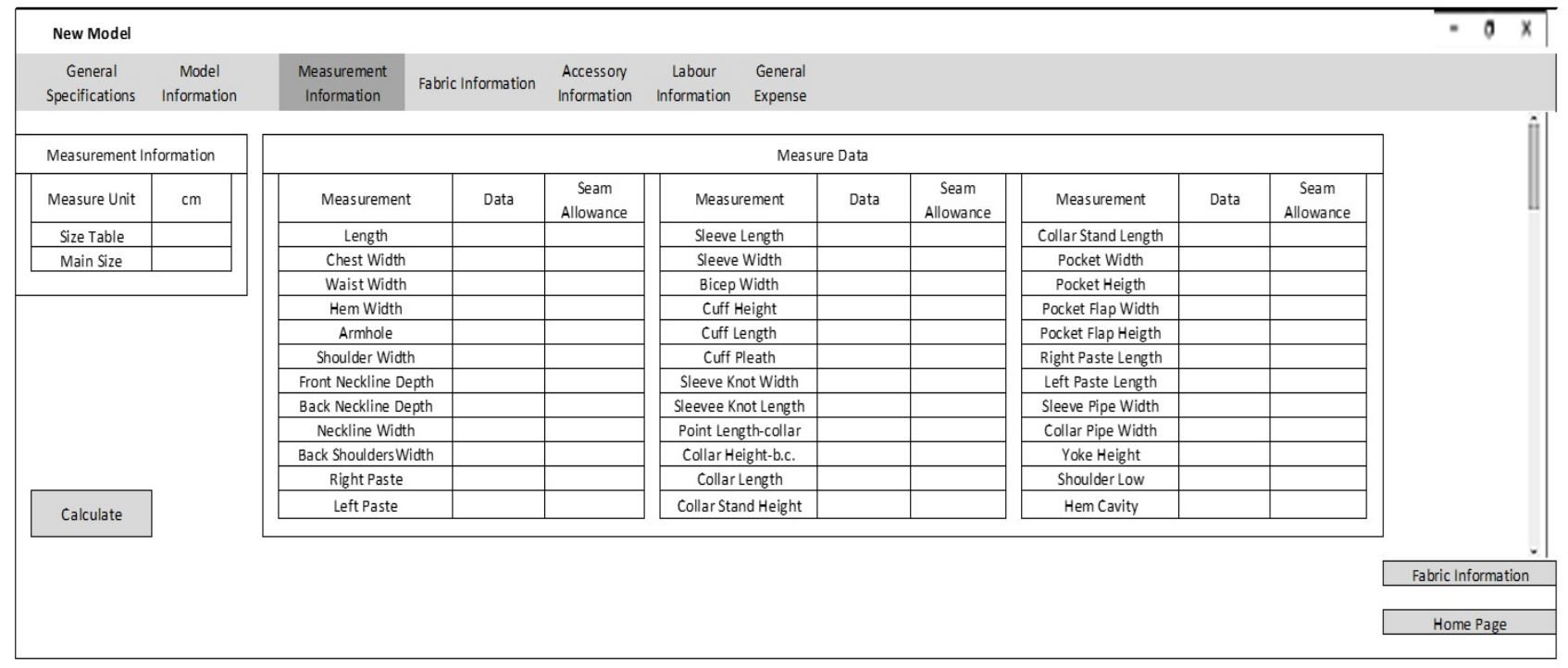

Figure 5. Measurement information interface

In the fourth stage fabric information section, unit fabric amount, unit fabric cost and order total fabric cost are calculated. Fabric width for the woven fabric, fabric width and weight information for the knitted fabric is required. After the data entry is provided, the system which is coded according to the fuzzy logic makes automatic marker drawing and finds the efficiency and calculates the amount of the fabric unit. Then, the cost of fabric is calculated by entering the information of waste and fabric price.

The amount of unit fabric is calculated differently in woven and knitted products. This difference is due to the determination of the fabric requirement of the knitted products in kilograms and the fabric requirement of the woven products in meters. Unit metering equation for woven products In Equation 6, the unit weight equation for knitted products is shown in Equation 7 (meter: $\mathrm{m}$, square meters: $\mathrm{m}^{2}$, gram: g).

The fifth stage is the calculation of the cost of auxiliary material. At this stage, the required material requirements can be selected for each section in the accessory archive section which is saved in the settings section. Material type, content, size, color and supplier are selected from this section. The cost of auxiliary material is calculated by entering the unit quantity and unit price information.

The sixth stage is the calculation of labor cost. The labor information section is classified as production labor (cutting, sewing, finishing) and extra labor (washing, embroidery, printing etc.). After the operation type and unit work price information is entered into the system, the total unit workmanship and order labor cost is calculated.

The seventh stage is the calculation of overhead cost. The overhead type is selected from the archive, unit and order overhead costs are calculated after entering the estimated production day.

After all these progressive cost data is entered, the HTM program provides a cost report. The unit pre-cost report is generated by the computer program with the report option at the pdf file type as the file name of the model name. The share of cost components in total product cost can be seen at cost analysis section of the report. Figure 6 shows the sample product unit pre-cost report.

Equation 6: Length in Metres Unit $(m)=\frac{\text { Total product area }\left(m^{2}\right)}{\text { Fabric Width }(m) \times \text { Productivity }}$

Equation 7: Weight in Grams Unit $\left(\mathrm{g} / \mathrm{m}^{2}\right)=\frac{\text { Total product area }\left(\mathrm{m}^{2}\right) \times \text { Fabric weight in grams }(\mathrm{g})}{\operatorname{Pr} \text { oductivity }}$ 


\begin{tabular}{|c|c|c|c|c|c|}
\hline $\begin{array}{c}\Delta \nabla \\
\cdots \\
\text { HTM }\end{array}$ & \multicolumn{4}{|c|}{ PRODUCT UNIT PRE-COST REPORT } & \\
\hline \multicolumn{6}{|l|}{ Order Information } \\
\hline Season & SS 17 & Product Group & Shirt & Related Section & Buyer \\
\hline Customer Name & R\&E & Product Sub-Group & Child & Related Person & R.Eren \\
\hline Model Name & QORO & Model Description & Boy's shirt & Cost Date & 22.12 .2016 \\
\hline Order No & YL1416 & Size Table & 74-EL & & \\
\hline Order amount & 25000 & Main Size & $\mathrm{s}$ & & \\
\hline Kind of Shipment & Packing & & & Euro & 3,6 TL \\
\hline Date of Shipment & 28.02 .2017 & & & Dollar & 3,5 TL \\
\hline \multicolumn{6}{|l|}{ Product Unit Cost } \\
\hline & & TL & $\%$ & & \\
\hline \multicolumn{2}{|c|}{ Total Unit Cost of Fabric } & 6,59 & 39,54 & & \\
\hline \multicolumn{2}{|c|}{ Total Unit Cost of Access ory } & 0,51 & 3,06 & & \\
\hline \multicolumn{2}{|c|}{ Total Unit Cost of Labour } & 6 & 36,02 & & \\
\hline \multicolumn{2}{|c|}{ Total Unit Cost of General Expense } & 3,56 & 21,37 & & \\
\hline Product Unit Cost & Profit & Product Unit Price & Order Price & & \\
\hline TL & $\%$ & TL & $\mathrm{TL}$ & & \\
\hline 16,66 & 12 & 18,65 & 16863,47 & & \\
\hline
\end{tabular}

Figure 6. Product pre-unit cost report

\section{FINDINGS}

The data required for the products examined in the study were taken from Gerber AccuMark program in the company studied woven group and from the Assyst-Lay CAD program in the company studied knitting group.
First, the total area of the product was compared. The actual pattern area information of the product is taken from the CAD system pattern design programs. Table 3 (for the shirt) and Table 4 (for T-Shirt) showed the percentage difference of total area between the actual and HTM program. The lower the curvilinear curve in the pattern parts, the closer the calculated area and the actual area are.

Table 3. The total product area of the shirt models

\begin{tabular}{cccc}
\hline Model name & HTM-Calculated area $\mathbf{( \mathbf { c m } ^ { 2 } )}$ & CAD-Actual area $\mathbf{( \mathbf { c m } ^ { 2 } )}$ & Difference $\mathbf{( \% )}$ \\
\hline S1 & 16900.3 & 16401.2 & 3.04 \\
S2 & 11930.4 & 11785.6 & 1.22 \\
S3 & 11390.8 & 11350.1 & 0.35 \\
S4 & 6986.9 & 6836.0 & 2.20 \\
S5 & 8944.3 & 9069.9 & -1.38 \\
S6 & 14111.2 & 13760.9 & 2.54 \\
S7 & 5597.7 & 5636.0 & -0.67 \\
S8 & 6077.0 & 5967.8 & 1.82 \\
S9 & 9403.9 & 9160.1 & 2.66 \\
S10 & 7044.8 & 6577.4 & 7.10 \\
S11 & 9087.2 & 8781.8 & 3.47 \\
S12 & 9599.3 & 9160.1 & 4.79 \\
\hline
\end{tabular}


Table 4. The total product area of the T-shirt models

\begin{tabular}{cccc}
\hline Model name & HTM-Calculated area $\mathbf{( \mathbf { c m } ^ { 2 } )}$ & CAD-Actual area $\mathbf{( \mathbf { c m } ^ { 2 } )}$ & Difference $\mathbf{( \% )}$ \\
\hline T1 & 17051.6 & 16052.3 & 6.22 \\
T2 & 12937.3 & 12236.4 & 5.72 \\
T3 & 14062.3 & 13992.2 & 0.5 \\
T4 & 12840.5 & 12447 & 3.16 \\
T5 & 9853.9 & 9603.6 & 2.6 \\
T6 & 9850.7 & 9610.7 & 2.49 \\
T7 & 15499.8 & 15542.2 & -0.27 \\
T8 & 9739.4 & 9443.05 & 3.13 \\
T9 & 9797.8 & 9482.4 & 3.32 \\
T10 & 10007.6 & 9382.8 & 6.65 \\
\hline
\end{tabular}

Secondly, the unit amount of product was compared. In the study, the estimated unit fabric amount at the pricing stage before the order confirmation, and the actual unit fabric amount determined after the production were taken from the CAD system marker programs. At this stage, the calculated by the HTM program, the estimation and the actual datas of the fabric unit amount were compared. Table 5 (for shirt) and Table 6 (for T-Shirt) show the triple unit fabric quantity values.

Table 5. The trio comparison of shirt unit length

\begin{tabular}{cccc}
\hline \multicolumn{4}{c}{ Unit Length Trio Comparison (Fabric Unit: m) } \\
\hline Model name & $\begin{array}{c}\text { HTM-Calculated length unit } \\
\text { (with loss) }\end{array}$ & $\begin{array}{c}\text { Company estimated unit } \\
\text { length (with loss) }\end{array}$ & $\begin{array}{c}\text { The actual unit } \\
\text { length }\end{array}$ \\
\hline S1 & 1.47 & 1.4 & 1.358 \\
S2 & 1.06 & 1.35 & 0.99 \\
S3 & 1.16 & 1.1 & 0.996 \\
S4 & 0.69 & 0.6 & 0.655 \\
S5 & 0.79 & 1.5 & 0.72 \\
S6 & 1.37 & 1 & 1.29 \\
S7 & 0.44 & 0.5 & 0.464 \\
S8 & 0.52 & 0.5 & 0.545 \\
S9 & 0.78 & 1 & 0.81 \\
S10 & 0.63 & 0.75 & 0.63 \\
S11 & 0.76 & 0.75 & 0.66 \\
S12 & 0.78 & 0.65 & 0.71 \\
\hline
\end{tabular}

Table 6. The trio comparison of t-shirt unit weight

\begin{tabular}{cccc}
\hline \multicolumn{4}{c}{ Unit Weight Trio Comparison (Fabric Unit: $\mathrm{g} / \mathrm{m}^{2}$ ) } \\
\hline Model name & $\begin{array}{c}\text { HTM-Calculated weight unit } \\
\text { (with loss) }\end{array}$ & $\begin{array}{c}\text { Company estimated unit } \\
\text { weight (with loss) }\end{array}$ & $\begin{array}{c}\text { The actual unit } \\
\text { weight }\end{array}$ \\
\hline T1 & 485.47 & 520 & 426.3875 \\
T2 & 377.21 & 470 & 395.67 \\
T3 & 410.01 & 570 & 458.934 \\
T4 & 227.055 & 270 & 239.726 \\
T5 & 287.31 & 330 & 256.872 \\
T6 & 287.21 & 330 & 311.0653 \\
T7 & 451.922 & 500 & 412.456 \\
T8 & 283.97 & 315 & 257.24 \\
T9 & 285.67 & 315 & 241.784 \\
T10 & 238.73 & 275 & 214.8372 \\
\hline
\end{tabular}




\section{CONCLUSION AND RECOMMENDATIONS}

Within the scope of this study, HTM computer program is designed in order to calculate the preliminary cost of the product. The program has been applied in the shirt and TShirt top garment groups in the weaving and knitting area.

According to the information taken by the companies regarding the chosen shirt models, the average difference is $7.41 \%$ between the estimated fabric unit meter in the precalculation and the actual fabric unit meters. When analysing the difference between the shirt model's estimated unit amount and actual unit amount, it was found that the company bought more fabric than needed for some shirt models. The difference is $5.15 \%$ between the actual fabric unit meter and the estimated fabric unit meter by the program after production. The program has provided a $2.26 \%$ improvement without exceeding the $15 \%$ limit in all models. The similarity rate between the calculated fabric unit amount value and the actual fabric unit amount value for the shirt models is $83.33 \%$. Figure 7 shows the trio comparison of the shirt's unit meter data. While the calculated value draws a parallel line with the actual value, the company estimated values show some deviation in some models.

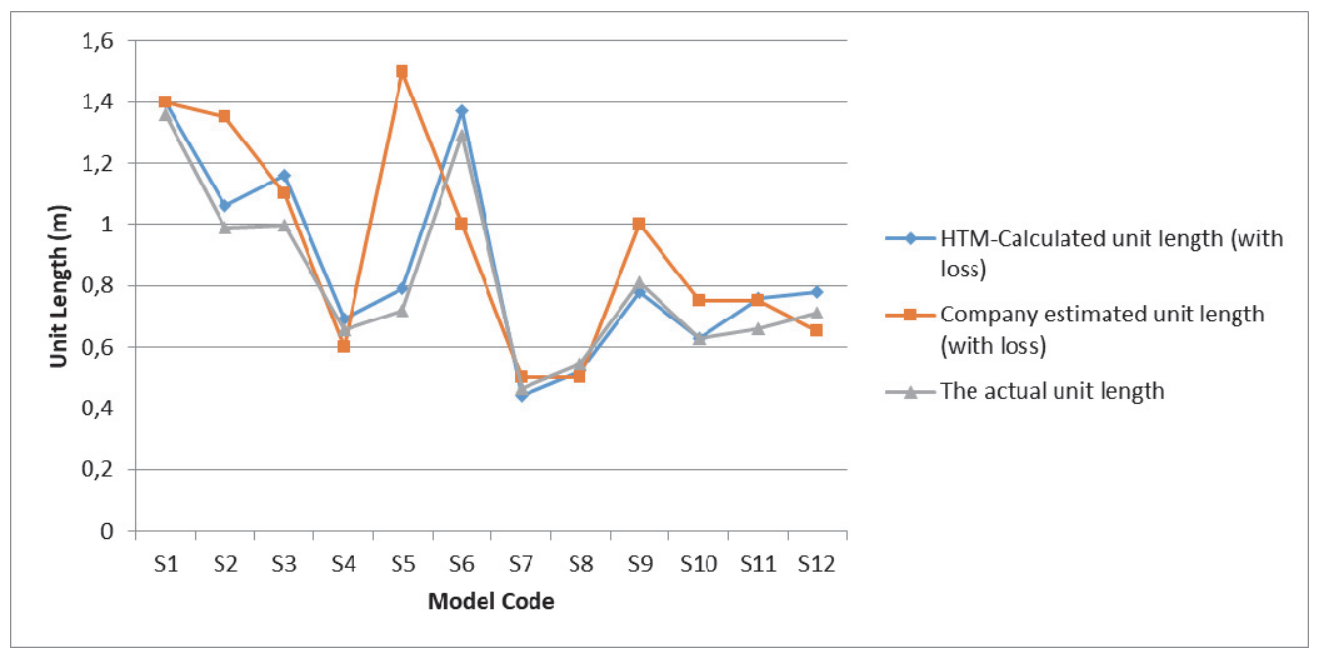

Figure 7. The trio comparison of the shirt's unit meter data

According to the information taken by the companies regarding the chosen T-Shirt models, the average difference is $17.33 \%$ between the estimated fabric unit weight in the pre-calculation and the actual fabric unit weight. The difference is $3.55 \%$ between the actual fabric unit weight and the estimated fabric unit weight by the program after production. The program has provided a $13.78 \%$ improvement without exceeding the $15 \%$ limit in all models. The similarity rate between the calculated fabric unit weight value and the actual fabric unit weight value for the T-Shirt models is $90 \%$. Figure 8 shows the trio comparison of the TShirt's unit weight data. While the calculated value draws a parallel line with the actual value, the company estimated values show some deviation in some models.

The reason why the unit fabric amount similarity rate in shirt models is lower than the fabric unit amount similarity in TShirt models is because woven models have more detailed patterns than shirts. While a classic shirt model is made up of 10 pieces, a T-Shirt is made up of 3 pieces. The calculated area and the fabric unit amount is affected by the amount of curves in the pieces.

The advantages of the program which is created within the scope of the study are as follows:

- To provide fast pricing information to the customer

- Speed and convenience in estimated cost calculation
- To be able to obtain close to real value with fabric cost calculation interface

- To calculate the amount of unit fabric by using the measurement table and to reduce the need for the model design section in calculating the unit fabric amount

- To be able to archive fabric and auxiliary information of companies by using the storage compartment of fabric and auxiliary material

- Thanks to the program archive, product variety is unlimited and calculate the cost easily

- To be able to add overhead cost to pre-cost through distribution keys

- Thanks to the reporting feature of the program, it is possible to easily access the product cost data of the previous periods.

Workmanship archive section can be added to HTM program which has fabric and accessory archive features. In this way, according to the product characteristics of the company can create labor costs database. The HTM program can be developed according to the variety of models in the industry. The program which works in the upper clothing weaving and knitting group can be expanded by adding the product features of the underwear and outerwear groups to the program. 


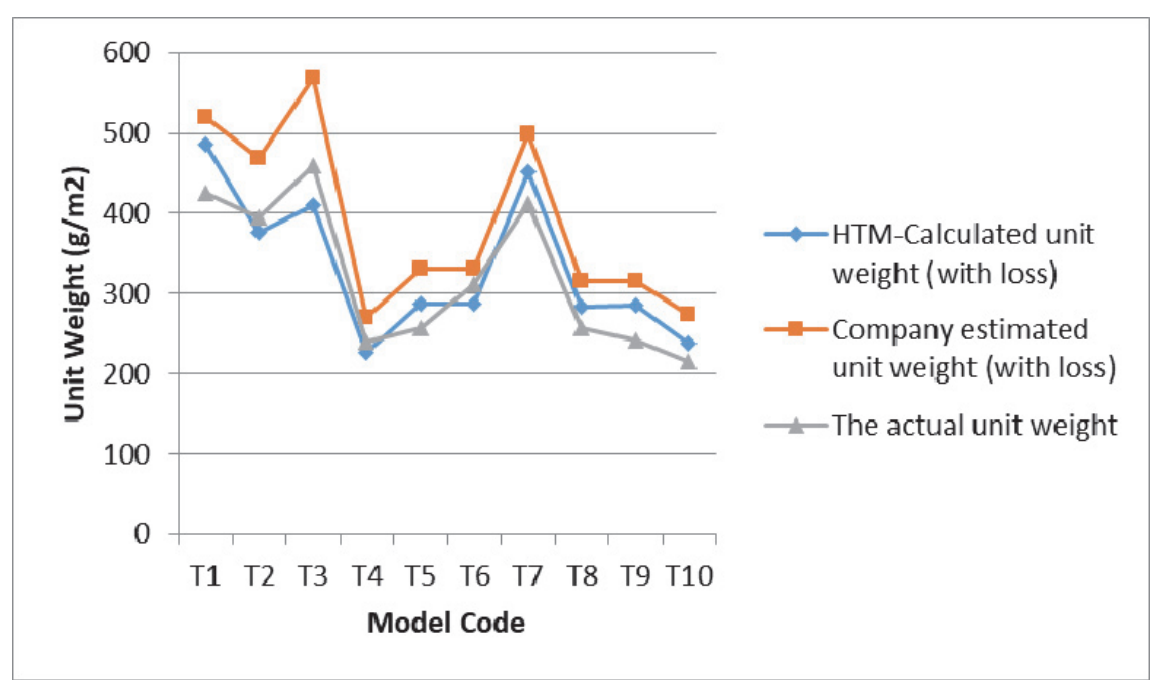

Figure 8. The trio comparison of the t-shirt's unit weight data

\section{REFERENCES}

1. The Scientific and Technological Research Council of Turkey (TÜBITAK). (July, 2003). Textile Panel. Vision 2023 Technology Foresight Project, Turkey.

2. Acar, V. \& Aktaş, R. (2010). Production and cost accounting function Interaction expectations from the cost accounting education: education model application proposal, Dumlupınar University Journal of Social Sciences, 27, 209.

3. Tewari, M. (2006). Is price and cost competitiveness enough for appare firms to gain market share in the world after quotas? A review, Global Economy Journal, 6(4). https://www.degruyter.com/view/j/gej.2006.6.4/gej.2006.6.4.1134/gej.20 06.6.4.1134.xml (Date of Access: 27.03.2018)

4. İskender, H. \& Ülker, Y. (2005). A reliable system in calculating true cost: activity based costing and the case of John Deere, Balıkesir University The Journal of Social Sciences Institute, 8.13: 189-217.

5. Takebira, U. M. (2016). Proficient costing procedure of a garment from yarn to consumer. American Scientific Research Journal for Engineering, Technology, and Sciences (ASRJETS), 19(1), 85-102. http://asrjetsjournal.org/index.php/American_Scientific_Journal/article/vi ew/1646/760 (Date of Access: 27.03.2018)

6. Öksüz, A. (2008). The calculation of the product cost and cost control in the textile sector (Master's thesis). Department of Business Administration Institute of Social Sciences Kahramanmaraş Sütçü İmam University, Kahramanmaras, Turkey.

7. Ferdousi, F. (2009). An investigation of manufacturing performance Improvement through lean production: a study on Bangladeshi garment firms, International Journal of Business and Management, 4.9: 106.

8. Eren, E. R. (2016). Fast estimating the cost of product unit on appare industry, (Master's thesis). The Graduate School of Natural and Applied Sciences Ege University, Izmir, Turkey.

9. Choudhary, A. S. (2015). Cost analysis in garment industry. International Journal of Recent Advances in Multidisciplinary Research, 2.9: 0702-0704.

10. Basic Education and Training Center-1 (TESMER-1). (2016). Cost accounting, Turkey Certified Public Accountant and Certified Public Accountant Basic Education and Training Center http://home.anadolu.edu.tr/ vekergil/resim/Dersler/Tesmer/Tesmer\%20 V-1.ppt (Date of Access: 28 Mart 2016)

11. Ministry of Science, Industry and Technology. (2013). Strategy document and action plan of textile, garments and leather products sector in Turkey 2015-2018, T.C. General Directorate of the Ministry of Science, Industry and Technology Industry, 75p.

12. Textile School. (2018). Garment costing. http://www.textileschool.com /181/garment-costing/ (Date of Access: 27.03.2018)

13. Kothari R. V. (2013) Fashion merchandising: garment costing, https://textiletoday.com.bd/fashion-merchandising-garment-costing/ (Date of Access: 27.03.2018)

14. Öğüt, K (2016). Cost-1 and 2. http://www.ymmogut.com/ dosyalar2/ haber_oku.php?haber_id=59 http://www.ymmogut.com/dosyalar2 haber_oku.php? haber_id=60D(ate of Access: 05.04.2016

15. Gökbulut, I. (2015). Cost accounting. http://giv.org.tr/userfiles/files/ Maliyet\%20Muhasebesi\%20(Do\%C3\%A7.\%20Dr.\%20R.\%20\%C4\%B0I ker\% 20G\%C3\%96KBULUT).pdf (Date of Access: 27.11.2015)

16. Dayanıklı, F. (2009). Development of a computer program on the calculation of production parameters in woven garment companies (Master's thesis). Dokuz Eylul University Graduate School of Natural and Applied Sciences M.Sc. Textile Engineering Department, Izmir, Turkey.

17. Vuruşkan, A. \& Bulgun, E. (2006). Pre-cost prediction in apparel industry: an investigation regarding clothing companies in Aegean Region, The Journal of Textiles and Engineer, 13.64: 48.

18. Savaş, M. (2006). Developing a manufacturing program on computer that maximize the profit at a garment industry that produces different style of apparels (Master's thesis). The Graduate School of Natural and Applied Sciences Dokuz Eylül University, Izmir, Turkey.

19. Başer, G \& Bulgun, E. Y. (2000). Development of a computer aided garment design program, Dokuz Eylul University Faculty of Engineering, Journal of Science and Engineering, 2(2), Izmir, 113-122s.

20. Vuruskan, A. (2005). Development a software about calculating the production parameters in knitted garment plants (Doctoral Dissertation, M. Sc. Thesis). Dept. Textile Eng., Dokuz Eylül Univ., Izmir, Turkey

21. Celik, N. \& Değirmenci, Z. (2013). Devoloping a software to calculate the unit cost of the double-fleece knitted fabric, Journal of Textiles and Engineer, 20(92), 11s.

22. Özdemir, S., Utkun, E. \& Yeşil, E. (2015). An application study to create a mobile-based cost calculation software regarding woven fabric manufacturing in small-scale textile businesses, Journal of Textile and Apparel, 25(3), 183p. 